\title{
Comparative Philosophy and the Tertium: Comparing What with What, and in What Respect?
}

\author{
Ralph Weber
}

Published online: 15 April 2014

(C) Springer Science+Business Media Dordrecht 2014

\begin{abstract}
Comparison is fundamental to the practice and subject-matter of philosophy, but has received scant attention by philosophers. This is even so in "comparative philosophy," which literally distinguishes itself from other philosophy by being "comparative." In this article, the need for a philosophy of comparison is suggested. What we compare with what, and in what respect it is done, poses a series of intriguing and intricate questions. In Part One, I offer a problematization of the tertium comparationis (the third of comparison) by examining conceptualizations of similarity, family resemblance, and analogy, which it is sometimes argued can do without a tertium comparationis. In Part Two, I argue that a third of comparison is already required to determine what is to be compared, and insofar as that determination precedes the comparison that tertium may be called "pre-comparative." This leads me to argue against incomparability and to show how anything can indeed be compared to anything. In Part Three, I relate my arguments to what is today commonly labelled "comparative philosophy." Finally, I raise some questions of ontology and politics in order to demonstrate the relevance of a philosophy of comparison.
\end{abstract}

Keywords Comparative philosophy - Intercultural philosophy · Tertium comparationis . Analogy · Family resemblance

\section{Introduction}

It is very ordinary for us to engage in comparisons of all sorts. We hardly ever reflect on that fact and, indeed, there is perhaps little to recommend such reflection in most cases, as most of our comparisons do not misfire, so to say, but are readily and aptly understood. We hence do not routinely (and do not expect that others might) call into question our comparisons, their starting-points, and the respect in which that which is compared is and is not thought to coincide. Nonetheless, such calling into question is in principle always possible and might be called for in cases where comparisons come

Ralph Weber $(\bowtie)$

URPP Asia and Europe, University of Zurich, Wiesenstrasse 7/9, 8008 Zurich, Switzerland

e-mail: ralph.weber@uzh.ch 
with claims of new scholarly insight or where they are used to advance religious, political or other aims. It might even be of some urgency in cases where it is impossible, with all good will, to disentangle scholarly claim from religious or political aim.

Christian Wolff, the German Enlightenment philosopher, experienced firsthand that comparisons matter and why it might be important to be very clear on what is compared with what and in what respect it is done. His vice-presidential farewell address at the University of Halle, "On the Practical Philosophy of the Chinese," on 12 July 1721 enraged not only the powerful Pietists, but also the Prussian King Frederick William I, who thereupon had Wolff deprived of his office and ordered to leave Prussian territory within 48 hours - or else he would be hanged, "bey Strafe des Stranges" (Albrecht 1985: 1i). What had Wolff said in his address to receive such a response? For one thing, he had likened the esteem in which Confucius was held by the Chinese to that of Moses, Mohammed, and Jesus, which, in the eyes of the Pietists, meant to put Confucius on a par with Jesus and hence constituted blasphemy. What is interesting here is that Wolff tried to show that the Pietists' interpretation of his comparison was grossly mistaken due to a wrongly conceived tertium comparationis (the third of comparison). The respect in which he had compared Confucius, Moses, Mohammed, and Jesus was not their character, nor the justification of their esteem, but simply the fact that they were held in such esteem by their followers (Wolff 1985: 17, 116-123). The whole affair influenced Wolff's philosophy greatly. Henceforth, he was of the firm opinion that any use of metaphor in philosophy should be accepted only if the tertium comparationis was clearly indicated and explained (Albus 2001: 30-31). ${ }^{1}$ The story about Christian Wolff is telling insofar as he expressis verbis refers to the tertium comparationis and does so only some 25 years after the earliest occurrence of the notion in a text of 1693 - and as it showcases the possible political use of comparisons. ${ }^{2}$

The tertium comparationis is one of four aspects in standard conceptualizations of comparison such as the following: (1) a comparison is always done by someone, (2) at least two relata (comparata) are compared, (3) the comparata are compared in some respect (tertium comparationis), and (4) the result of a comparison is a relation between the comparata on the basis of the chosen respect. Put simply, if one sets out to compare, say, the notion of human nature in the Mengzi 孟子 (Mencius) and in the Xunzi 苻子, one assumes or asserts a notion of human nature about which no more must be claimed than that it is equally relatable to both. In this example, the Mengzi and the Xunzi are the

\footnotetext{
${ }^{1}$ The passage by Wolff mentioning the tertium comparationis reads in the original: "Bei einer jeden verblümten Redensart (metaphora) haben wir zwei Begriffe, deren einer ohne dem andern seyn kan, aus deren Vergleichung aber durch die (Abstraktion) Absonderung ein gewisser dritter Begriff entstehet, welcher etwas vorstellet, das in beyden zugleich befindlich ist, und deswegen die Sache, worinn die Vergleichung geschiehet (tertium comparationis), genennet wird, auser welchem die Aehnlichkeit, darauf die verblümte Redensart (metaphora) sich gründet, sich nicht erstrecket." [With each allusive figure of speech (metaphora) we have two concepts, of which each can be without the other, and of the comparison of which by way of dissociation (abstraction) a certain third concept emerges, which presents something present in both simultaneously. Therefore the matter in which the comparison occurs is called tertium comparationis. Beyond it, the similarity, on which the allusive figure of speech (metaphora) is based, does not reach.] (Wolff 1981: 81-82). ${ }^{2}$ Although the subject matter expressed by the tertium comparationis is dealt with in the context of metaphors in Plato (Laches 192a-b), Aristotle (Topics 140a8-13; Poetics 1457b; Rhetoric 1406b), Cicero (De Oratore, III, XXXIX, 157), and Quintillian (Institutio Oratoria, VIII, VI, 8), the expression itself is attested only as late as in the Baroque period. The Enzyklopädie Philosophie und Wissenschaftstheorie mentions Erhard Weigel and his 1693 book Philosophia Mathematica (Thiel 2004: 239-240).
} 
two comparata, whereas the notion of human nature is the tertium comparationis. The tertium comparationis hence denotes a point of commonality, and I shall use that expression to mean what from one point of view could be called minimal and maximal conceptions of "commonality": minimally, the expression refers to a "common" respect (equally relatable to both comparata) and, maximally, the expression refers to something like a "common" property (shared by both comparata). ${ }^{3}$ In comparative studies, the necessity of such a point of commonality is usually taken for granted, and it is frequently acknowledged in introductions and compendia. The tertium comparationis and the other aspects of comparison, however, have not been the topic of much exclusive and probing scholarly attention. This includes philosophical attention, which is curious enough for at least two reasons.

Comparison, it is generally agreed, plays a fundamental role in the practice and in the subject-matter of philosophy. ${ }^{4}$ For Nicholas of Cusa, every inquiry in which one seeks to get to know something unknown proceeds by means of comparison. ${ }^{5}$ John Locke considers comparison to be that "operation of the mind" upon which "depends all that large tribe of ideas comprehended under RELATION" (Locke 1997: 154). For Immanuel Kant, comparison is one of reason's "three logical operations" (i.e., comparison, reflection, and abstraction), these three being "the most fundamental and most general conditions for the generation of any concept." 6 Given its fundamentality, it seems a curiosity that not one such canonical philosopher has ever set out to write an extensive philosophy of comparison (dated and hardly extensive, cf. Brunswig 1910). To be sure, plenty of philosophical works (as well as works in other disciplines, e.g., comparative literature, sociology, etc.) offer interesting discussions on related notions such as resemblance, similarity, sameness, identity, or difference, on which one can draw to envisage a philosophy of comparison and to delve into the problematic of the tertium further. This problematic touches on some of the "big questions" in philosophy (e.g., the one and the many), but also on many debates in more recent philosophy (e.g., "resemblance nominalism," cf. Rodriguez-Pereyra 2002; or the discussion over "sortals," i.e., whether they are best to be understood as universals, predicates, or concepts, cf. Wiggins 2001). All of that, however, in no way belittles but rather increases the curiosity.

\footnotetext{
${ }^{3}$ It is of course questionable whether what is relatable is not also-for that reason alone - in an important sense shared. The question is further dealt with in 3.3 below.

${ }^{4}$ In the Historisches Wörterbuch der Philosophie it is noted that although comparing is ubiquitous in philosophy and the sciences it is a key term in neither (Schenk and Krause 2001: 677).

5 "Comparativa igitur est omnis inquisitio medio proportionis utens." See: Cusanus, De docta ignoratia I, 1, 3 (Elberfeld 1999: 144-145).

6 "Um aus Vorstellungen Begriffe zu machen, muss man also komparieren, reflektieren und abstrahieren können; denn diese drei logischen Operationen des Verstandes sind die wesentlichen und allgemeinen Bedingungen zu Erzeugung eines jeden Begriffs überhaupt.-Ich sehe z.B. eine Fichte, eine Weide und eine Linde. Indem ich diese Gegenstände zuvorderst unter einander vergleiche, bemerke ich, dass sie von einander verschieden sind in Ansehung des Stammes, der Äste, der Blätter u. dgl. m.; nun reflektiere ich aber hiernächst nur auf das, was sie unter sich gemein haben, den Stamm, die Äste, die Blätter selbst und abstrahiere von der Grösse, der Figur derselben u.s.w.; so bekomme ich einen Begriff vom Baume” (Kant 1800: §6). [English translation: "To make concepts out of representations one must thus be able to compare, to reflect and to abstract, for these three logical operations of the understanding are the essential and universal conditions for generation of every concept whatsoever. I see, e.g., a spruce, a willow and a linden. By first comparing these objects with one another I note that they are different from one another in regard to the trunk, the branches, the leaves, etc.; but next I reflect on that which they have in common among themselves, trunk, branches and leaves themselves, and I abstract from the quantity, the figure, etc., of these; thus I acquire a concept of a tree" (Kant 1992: 592).]
} 
Perhaps the lack of a philosophical treatment of comparison has been remedied by the rise of "comparative philosophy," which literally seems to distinguish itself from other philosophy simply by being "comparative."7 However, this is — generally speaking — not so. For some earlier commentators, this would not even be desirable. Raimundo Panikkar is of the opinion that "the independent status of comparative philosophy should be distinguished from the conventional notions of comparison used by all systematic thinkers" (Panikkar 1988: 117). Similarly, Jean-Paul Reding maintains in his discussion of comparative philosophy that "the comparative method must not be confused with the mere act of comparing" (Reding 2004: 1). In this article, I set out to embrace what they reject; namely, that "every philosophy is comparative philosophy" (Panikkar 1988: 118)-although this is a matter of degree, and one might want to reserve the label "comparative philosophy" for a certain degree only. The point is that "comparative philosophy," as it is understood by many, can lay claim to an independent status precisely because it rests on largely unquestioned conventional notions of comparison. Although some methodological issues (regarding incommensurability, universalisms and relativisms of all sorts, translation, etc.) frequently have formed the topic of discussion, little has been written in "comparative philosophy" about comparison itself. ${ }^{8}$ As far as scholars have discussed the topic, they have usually presupposed one or another set of comparata such as East and West, Greece and China, rational Europe and mystical India, or Chinese, Japanese, and Korean cultures. However, what we do when we compare and the "logical operation" of comparing, which the tertium comparationis represents, has hardly been touched. The little reflection that comparison has received in comparative philosophy thus stands out as a second curiosity.

In this essay, no full-fledged philosophy of comparison is attempted. Rather, I wish to point out some specific aspects, a discussion of which any such attempt would have to include. There are three parts to the essay. In Section 2, I discuss the tertium comparationis and offer a problematization in order to illustrate that there is sufficient ambiguity and remaining confusion so as to recommend the topic for further philosophical work. Particularly, I investigate whether rationalizations of similarity, family resemblance, and analogy can do without a tertium comparationis. In Section 3, I argue that it is a mistake to locate the third of comparison only in the tertium comparationis as that in which respect the comparata are to be compared. There is a tertium already required to determine the comparata, and insofar as that determination precedes the comparison that tertium may be thought of as "precomparative." This leads me to argue against an incomparability claimed on grounds of incommensurability and to show how anything can indeed be compared to anything. In Section 4, I relate these preliminary

\footnotetext{
${ }_{7}$ Raimundo Panikkar offers a series of reflections on the meaning of "comparative" in "comparative philosophy": "Why do we say 'comparative philosophy' and not 'compared philosophy' as the Romance languages say (filosofia comparada and not comparativa), or 'comparing philosophy' (vergleichende Philosophie, not vergliechene) as the Germanic languages suggest?" (Panikkar 1988: 120)

${ }^{8}$ See, for instance, Mou 2010. Among the few to make comparison a topic is Wilhelm Halbfass, who explicitly raises the question whether comparison might be a "suitable topic for comparative studies" (Halbfass 1985: 3). A recent contribution is the article on philosophical comparison by ZHANG Xianglong, who is out precisely to reject the "commonly believed [view] that philosophical comparison depends on having some common measure or standard between and above the compared parts" (Zhang 2010: 90). That "comparative philosophy" has thus far shown little concern for the notion of "comparison" is confirmed by the author of a recent monograph on the methodologies of "comparative philosophy" (Smid 2009: 4-5). For a more comprehensive discussion of the state of the philosophy of comparison in comparative philosophy, see Weber 2013.
} 
investigations into a philosophy of comparison to what is today commonly referred to and variously institutionalized as "comparative philosophy." In the conclusion, I connect my argument about the "precomparative" tertium to questions of ontology and politics in order to demonstrate the relevance and need for a philosophy of comparison.

\section{Problematization of the Tertium Comparationis}

The third of comparison denotes a point of commonality without which no comparison seems possible. It provides what Geoffrey Lloyd calls the "points of contact that allow comparisons to proceed" (Lloyd 2004: 32). These points might be very differently approached, turning on claims about questions or ambitions in some way shared by two authors, their treatment of the same philosophical problem or their investigation of the same phenomena. They might be thought of as pertaining to the comparata themselves (as the amount of labor that went into products made them comparable in Engels's view) or as being imposed on the comparata (as money was to make products comparable and fit for trade in Aristotle's view). ${ }^{9}$ They might lend themselves to idealist or materialist, nominalist or realist metaphysical positions (cf. Butchvarov 1966). However it is conceived, the tertium comparationis has to be equally relatable to each of the comparata. If I compare, for instance, the Socratic dialogue Euthyphro and the Confucian Analects 13.18 with respect to "piety," then I posit a claim that the notion, the concept or the "thing" is relatable to both texts. To substantiate my claim, I might want to

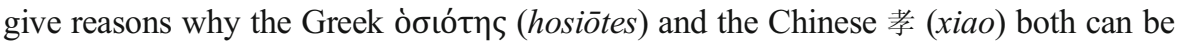
taken as expressions sufficiently equivalent with the notion of piety, or as expressing the same concept of piousness (cf. Murphy and Weber 2010). To be so related, it seems that the tertium comparationis has to be in some basic sense a universal, as that which, following the classic Aristotelian account, is of such a nature as to be predicated of many (quod aptum natum est esse in pluribus, as Peter of Spain put it; see Petrus Hispanus 1972: 17. See also Aristotle 1963: 47). Of course, this is as yet no more than a roughand-ready, first approximation of the tertium comparationis. What does "equally relatable" mean? How do we have to conceive of that "commonality"?

If it can be shown that there are different ways of conceptualizing the tertium comparationis, that is, different ways of relating and different ways of conceiving commonality, the obviousness with which comparison has thus far been treated is called into question. Some very basic ways can easily be distinguished. For one thing, the tertium comparationis may be related to the comparata as a whole is to its parts, a substance to its accidents, an idea to its instances, or a generic concept to its subsumed concepts, and so on. For the purposes of this paper, I would like to highlight and discuss briefly three challenges to the thesis that a comparison always involves one or more points of commonality which upon reflection can be identified. The thesis is challenged by those who insist that two relata may be related respectively by way of

\footnotetext{
${ }^{9}$ See Engels: "Der Tauschwert setzt ein tertium comparationis zum Vergleich herangezogenes Drittes voraus, woran er gemessen wird: die Arbeit, die gemeinsame gesellschaftliche Substanz der Tauschwerte, und zwar die gesellschaftlich notwendige Arbeitszeit, die in ihm vergegenständlicht ist" (Engels 1968: 245). [English translation: "Exchange-value presupposes a tertium comparationis by which it is measured; labor, the common social substance of exchange-values, to be precise, the socially necessary labor-time embodied in them" (Moore and Aveling n.d.).] See also Marx 1962: 73-74, and Aristotle 2000: 91.
} 
similarity, family resemblance, or analogy, all of which are held to do without an assertion of commonality. I will fend off these challenges by arguing the opposite, namely that similarity, family resemblance, and analogy are ways of comparison that in some way or other rely on assertions of commonality. At the same time, this is to show that there are very clearly many different ways of conceptualizing the tertium comparationis.

\subsection{Similarity}

The first challenge is similarity, although not in the form of two comparata being similar in some common respect (which, however, is the form usually advocated in the literature, notwithstanding the obvious commonality underlying the similarity), but in the form of them being similar in some similar respect (which is not explicitly advocated in the literature, but theoretically is posing a more penetrating challenge). For someone could easily hold that he or she is comparing two relata which do not share any point of commonality that makes them appear similar but simply a point of similarity that has that same effect. The difference may be illustrated as follows (Fig. 1 and Fig. 2):

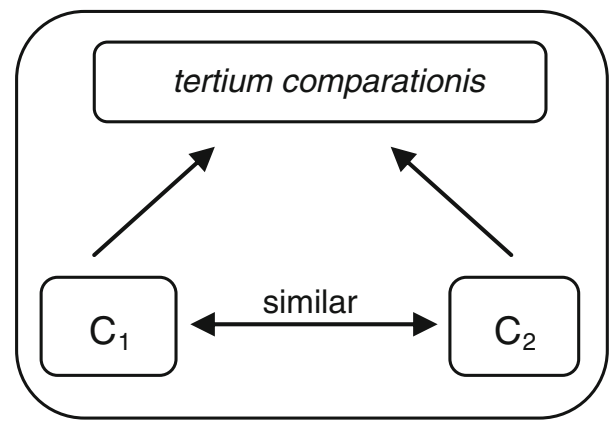

Fig. 1 Similarity in a common respect



Fig. 2 Similarity in a similar respect 
The question is whether "similarity in a similar respect" can be conceptualized without a point of commonality. An obvious objection is that the similarity between the tertium and the quartum in Fig. 2 seems to rely again on a common respect. However, that need not be so, for that similarity again could be one in a similar respect and so on ad infinitum. ${ }^{10}$ For example, consider two pamphlets deemed to be similar in a similar respect, say, the similarity of both being about similar notions of liberty (the tertium and the quartum of the comparison). That similarity, that is, of the notions of liberty, is in turn founded on both being connected to similar notions of individualism (the quintum and sextum), which again is linked to similar notions of community and so forth. The possibility of an infinite regress seems to point to a conceptualization of a comparison without a point of commonality. A similarity without commonality can hence be conceptualized as a sort of similarity infinitely passing from one respect to the next. ${ }^{11}$ It is, however, hard to accept such a conceptualization as the ground on which a comparison is to proceed because it seems impossible in practice exhaustively to substantiate what is a claim based on inexhaustibility; no complete account of such a similarity could be produced.

There is perhaps a further problem with that conceptualization, namely with regard to "sensible qualities" of objects. Panayot Butchvarov has argued that the complexity of such qualities and hence the possibility to continue the regress of similar respects for long is rather limited. He takes the example of two books resembling each other in respect of color and lists the characteristics of hue, saturation, and brilliance as possible qualities of color. His point is that

... with the diminishing degree of complexity in objects which are said to resemble each other, the need of specifying the respect of the resemblance diminishes. Perhaps to assert that the color of $a$ is like the color of $b$ would still be misleading, because the two colors may resemble each other in respect to hue but not in respect to brilliance. But will any ambiguity be found in asserting that the hue of the color of $a$ is like the hue of the color of $b$, or is more like the hue of the color of $b$ than it is like the hue of the color of $c$ ? [...] Clearly, therefore, there are cases of resemblance in which no specification of a respect is needed. (Butchvarov 1966: 38)

Butchvarov seems to say that "no specification of a respect is needed" because one has arrived at a quality for which it seems impossible to sense respects that would allow for further differentiation. He refers to these qualities as "simple qualities" or "simple characteristics" (anticipating talk about mereological simples in contemporary metaphysics; cf. Markosian 1998). It is of course an open question whether one would also arrive at something like simples when dealing not with objects but with notions or concepts (the example above of the two similar pamphlets suggests that it is not so). Nonetheless, what does Butchvarov's argument tell us about the question of a point of commonality? The possibility of a situation in which no further respect can be asserted anymore does not result in a similarity without a commonality, but rather in a straightforward commonality.

\footnotetext{
${ }^{10}$ Edmund Husserl thinks this case impossible as it inevitably leads to the "most perverted ingressus in infinitum" (Husserl 1901: 112-113).

${ }^{11}$ Note that in the regress similarity itself is a sort of universal, but that does not lead to Russell's resemblance regress as that universal is not what is claimed to sponsor the commonality of the two comparata.
} 
The hue of the two colors in his example is qualitatively identical. To say that it is not would mean to appeal to something along which the two hues could be differentiated, which is precisely what is claimed to be impossible. Hence, there is nothing like qualities of comparata (or, for that matter, also no comparata themselves) being tout court similar. ${ }^{12}$ Similarity is always in some respect, and where no such respect can any longer be ascertained (apart from their spatio-temporal location, of course, which justifies our talk of two colors), we cannot possibly be dealing with two resembling qualities, but we are dealing with one and the same quality. We seem in practice to arrive at such a common quality pretty quickly in our attempts to differentiate qualities of objects.

Perhaps this view of similarity is too narrow-minded. In the end, there are many "similar" concepts such as resemblance, semblance, affinity, and likeness, some of which I have just used interchangeably - surely somewhat carelessly. Michel Foucault has pointed out the rich semantic web of resemblance as it presents itself in 16th-century Latin writings. He lists: "amicitia, aequalitas (contractus, consensus, matrimonium, societas, pax et similia), consonantia, concertus, continuum, paritas, proportio, similitudo, coniunctio, copulas," as well as convenientia, aemulatio, analogy, and what he calls the play of sympathies. Foucault elaborates on the last four "similitudes," which to him are essential and which in his account in The Order of Things clearly capture different ways of conceptualizing resemblance (Foucault 2002: 20). ${ }^{13}$ The fact that Foucault can point to a semantic web suggests that each of the above notions could profitably be examined for a specific conceptualization of resemblance, which could serve as a basis from which to compare or to examine comparisons. It might be that some such conceptualization would yield yet another way of relating two resembling comparata without appeal to a point of commonality. ${ }^{14}$

\footnotetext{
${ }^{12}$ Note that similarity and resemblance have often been discussed in that manner. Bertrand Russell's famous resemblance regress, for instance, precisely relies on two patches of white (to stay with his example) simply resembling each other (cf. Russell 1912: 95). While in ordinary discourse we often utter statements of that kind, if pressed, we would I think still point to a respect on which the claimed resemblance rests. This is also not to ignore that "bare similarity" or "primitive, flat-out similarity" is being discussed in metaphysics, and the proponents of which are precisely out to challenge the view that "if A and B are similar, they are similar with respect to some measure (and perhaps dissimilar with respect to some other)." For one such argument, which holds that particularized properties (unlike objects) are similar, but not similar in any specific regard, see Heil 2003: 132 and ch. 14. Another interesting work in contemporary metaphysics that postulates tout court resemblance between two particulars without use of an extra entity for the resemblance itself is the version of resemblance nominalism defended by Gonzalo Rodriguez-Pereyra (2002).

${ }^{13}$ In the next chapter, Foucault discusses signatures, without which, he says, we would not possibly be aware of any resemblances: "There are no resemblances without signatures. The world of similarity can only be a world of signs" (Foucault 2002: 29).

${ }^{14}$ In another of his writings, Foucault seems to suggest precisely this when distinguishing between similitude and resemblance: "Resemblance presupposes a primary reference that prescribes and classes. The similar develops in series that have neither beginning nor end, that can be followed in one direction as easily as in another, that obey no hierarchy, but propagate themselves from small differences among small differences. Resemblance serves representation, which rules over it; similitude serves repetition, which ranges across it. Resemblance predicates itself upon a model it must return to and reveal; similitude circulates the simulacrum as an indefinite and reversible relation of the similar to the similar" (Foucault 1983: 44).
} 


\subsection{Family Resemblance}

An interesting case is family resemblance, which is a fashionable notion among those who wish to disassociate their comparisons from essentialist claims of commonality. ${ }^{15}$ In the case of family resemblance, no point of commonality that would suffice to characterize the comparata and just the comparata seems determinable (which is the whole point of it!). In a comparison, say, of traditional architecture in respect of houses, related by means of family resemblance, houses may be included because they resemble each other in characteristics such as having a foundation, solid internal and external walls, doors, windows, and roofs, although not each and every house has to feature all of the characteristics. Hence, Malaysian Kampung-houses, which are built on stakes and thus lack a foundation, traditional Japanese houses with mobile internal walls made out of paper, and the window-less Sami kåta could all be included in the comparison (which conceptualizes houses along characteristics). It seems as if family resemblance could serve as the basis for a comparison without a determinable tertium comparationis. However, the tertium comparationis remains determinable, only that instead of one point of commonality there are several such points. ${ }^{16}$ For how would one be able to check for the characteristic of having a window or a foundation (unless, of course, one is willing to understand the characteristic "window" again on the basis of a family resemblance, which if carried to a theoretical extreme would come at the cost of an infinite regress)? There is, it seems, no way around points of commonality.

This raises an interesting question: is a comparison between two comparata in respect of a third still a comparison if the existence of that third is affirmed in the one comparatum but denied in the other? Can I compare houses for having windows if one of the comparatum is a Sami kåta? What about a Sami kåta and a North-American tipi, neither of which have windows? Would that not make anything comparable with just anything else? This is precisely the thesis that I shall defend in the second part, but here I do not give my argument against incomparability. It suffices to point out that in many comparisons, this is exactly the practice and is perfectly understood as posing no problem. It is like using criteria in a comparison and setting the value 0 if a criterion is not affirmed and the value 1 if it is. When, for instance, comparing European countries with regard to their legal system, one likely finding is precisely that there is judicial review of federal legislation in Germany, but none in Switzerland (it seems, however, not irrelevant that Switzerland possibly could have judicial review, which is the difference between setting the value 0 and judging the

\footnotetext{
${ }^{15}$ Unfortunately, the notion is usually left unexplained or is merely complemented by a fuzzy reference to Wittgenstein's Philosophical Investigations or worse to his "theory" of family resemblance-as if Wittgenstein's remarks on the notion in PI would be clear or would make up a theory....

${ }^{16}$ Not to be mistaken, I am not claiming that Wittgenstein's notion of family resemblance is necessarily linked to a list of characteristics. What he had in mind might indeed have been more like an immediate resemblance ("look and see!"). What I am claiming is that when reasoning about a perceived family resemblance, we would do something like give a list of characteristics. Wittgenstein himself does something like that when reasoning about the family resemblance among games and members of a family (see Wittgenstein 1958: 31-32). See also the illustration in Glock 1996: 121. For Wittgenstein on comparing, commonality, and similarity, see Wittgenstein 1965: 86-87, 132-134.
} 
criterion to be "non-applicable"). ${ }^{17}$ It would be absurd to claim that comparisons following such a pattern are not "really" comparisons. There is an important lesson to draw from this. It makes clear that there are cases where the person who does the comparison obviously sets the tertium comparationis, at least for some of the comparata. That is to say, an argument that a tertium comparationis must always somehow be present in all comparata is indefensible, that is, "present" in a stricter sense, for example, be part of it or in any case more than just being related. ${ }^{18}$

\subsection{Analogy}

The last challenge I want to raise is analogy, which is often pitted against comparison and particularly against a rationalist account that stresses the role of a tertium comparationis. A recent example is Giorgio Agamben, who claims that analogy draws on a third other than the one of comparison, that is, one

... not in the sense of a third term that is homogenous with the first two and whose identity could be defined by means of a binary logic. The analogue (or the paradigm) can appear as the tertium comparationis only if seen from the standpoint of dichotomy. The third of analogy gains its constitution mainly by deidentification and neutralization of the first two positions which thus become indistinguishable from each other. The third is that indistinguishability, and any attempt to determine it via bivalent caesura has to come upon indistinguishability. (Agamben 2009: 24; my translation)

It seems as if analogy for Agamben does not depend on a point of commonality or insofar as it does that the point cannot be distinguished, let alone be determined. Instead of a tertium comparationis there is an indeterminable tertium analogiae; analogy hence can be conceptualized without reference to comparison. ${ }^{19}$

Analogy presented as in no need of a determinable commonality has been interpreted by others as a philosophical vice, a sort of carte blanche for all the most dubitable claims (cf. Bouveresse 1999). Analogies, as Robert Musil has ironically pointed out, are "always right in some sense or other" (Musil 1990: 135). Most analogies, however, require just a bit of effort-what classical rhetoric called inventio - to identify the posited or asserted commonalities. In a caricature of analogical reasoning (as well as racist stereotypes) in Oswald Spengler's The Decline of the West, Musil relates the following example:

\footnotetext{
${ }^{17}$ What seems an impossible claim is to say that anything is comparable with anything in "every" thinkable specific respect. One cannot compare two comparata in a respect which by definition is not applicable to them. However, the two comparata of course remain comparable in at least a second respect, namely in the applicability of the first respect.

${ }^{18}$ That the common respect in which something is similar has not to be present in the comparata - at least not in an unmediated way - is also suggested by the fact that a theory is easily imaginable according to which two "things" are similar in respect of being dissimilar to all other things, but that dissimilarity will again be in a respect which — upon reflection — can be determined.

19 An inference from analogy is usually taken as proceeding from part(icular) to part(icular) because it does not recur on a general rule or principle, which is why the conclusion can only claim probability. However, an analogy still recurs on a similarity, for which a point of commonality seems indispensable.
} 
There are lemon-yellow butterflies, and there are lemon-yellow Chinese. In a certain sense, then, one can say that the butterfly is the winged, middle-European, dwarf Chinese. Butterflies and Chinese are both familiar as images of sexual desire. Here the thought is formulated for the first time of the previously unrecognized commonality between the great ages of lepidopteral fauna and Chinese culture. That butterflies have wings and the Chinese do not is only a superficial phenomenon. If ever a zoologist had understood anything about the ultimate and deepest ideas of technology, it would not have been left to me to be the first to disclose the significance of the fact that butterflies did not invent gunpowder precisely because the Chinese had done so already. The suicidal predilection of certain kinds of nocturnal moths for bright light is a relic of this morphological connection to Sinology, a connection hard to explain in terms of everyday reason.

It really makes no difference what it is to be proved by such means. (Musil 1990: 136, italics mine; cf. also Bouveresse 1999: 21-22)

Note, however, that the analogy in this ad absurdum-example poses no problem as to what commonality sustains it, namely the equal relation to "lemon-yellow." Here, what is presented as an analogy is an analogy based on a distinguishable and determinable tertium comparationis. Indeed, according to many accounts, analogies turn on such commonalities, which upon reflection may be determined. ${ }^{20}$ We should hence be careful to give in too hastily to the idea of analogy as by definition in no need of a tertium comparationis.

To take an example: many interpreters of the Mengzi 孟子 have pointed out the frequent use of analogy in that text. David Wong has examined the kind of analogical reasoning in some of the text's most prominent passages. His examination of Mengzi $1 \mathrm{~A} 7$ yields that King Xuan 宣王 "likens the eyes of the innocent man to the eyes of the ox, and likens the compassion he feels for the innocent man to his feeling for the ox," whereupon Mengzi "urges him to compare the plight of the ox to that of his people and to compare his compassionate reaction to the ox to what ought to be the compassion he feels for his people" (Wong 2002: 197). Wong sees in the analogical reasoning in the Mengzi a kind of casuistry:

In encountering new situations, we determine what sort of ethical reaction to the new situation is correct by asking which cases in which we've had sprout intuitions are relevantly similar. We then determine what reactions to the new situations would be sufficiently similar to the relevant sprout intuitions, and we conduct such comparisons without the mediation of any general principle. Reasoning, in Mengzi, is careful attention and comparing to a concrete paradigm. (Wong 2002: 202-203, italics in original) ${ }^{21}$

\footnotetext{
${ }^{20}$ See, for instance, the entry in the Encyclopaedia Britannica: "Speaking generally, [analogy] is that process whereby, from the known agreement of two or more things in certain respects, we infer agreement in some other point known to be present in one or more, but not known to be present in the other or others" (italics mine).

${ }^{21}$ The expression "sprout intuitions" refers to the Mengzian view that every human person possesses the four sprouts (si duan 四端) of commiseration, shame, courtesy, and right and wrong (see Mengzi 6A:6).
} 
The Mengzian analogy does not rely on "a general principle specifying relevanceconstituting characteristics," but its underlying casuistry draws on the criterion of sufficient similarity to reason that the related cases are "in the same category" (Wong 2002: 202). It is very clear that analogy in the Mengzi on this reading is not pitted against comparison but depends on it. The question whether analogy proceeds by means of a general principle or by casuistry based on sufficient similarity is really about two different ways of conceptualizing the tertium comparationis, as both involve a point of commonality, be it the common principle or the common respects in which two cases are found similar.

\section{Problematization of the "Pre-comparative" Tertium}

The third of comparison plays an even more crucial role in the determination of the comparata which one then sets out to compare in one or another respect. As a matter of fact, there is already a sort of tertium comparationis put to work in that determination, and insofar as the determination precedes the comparison this tertium may be thought of as "pre-comparative" - and I shall distinguish throughout this paper between the tertium comparationis as the respect in which determined comparata are compared and the "pre-comparative" tertium which is at work in the setting up of the comparison, that is, in the determination of the comparata.

In comparative studies, the placing of one comparatum next to the other for the sake of subsequent comparison is not done purely at will but on the basis of a presumed or asserted relation, which is expressive of a claim of resemblance or dissemblance (or of identity or difference) and thus is also the result of prior comparison(s): "pre-comparative" is in this sense always "post-comparative." However, that really means that the determination of the comparata at least upon reflection involves the positing or asserting of a point of commonality. Tim Murphy and I have referred to this as the "assertions of commonalities," by which we mean the "assumptions or presuppositions of commonality that serve to justify the comparative exercise in the first instance" (Murphy and Weber 2010: 187). In what follows, I (1) introduce the "pre-comparative" tertium, (2) argue that incomparability on grounds of mere incommensurability is not warranted, and (3) address how anything can be compared with anything in some respect.

\subsection{Where There are Two, There are Three}

Consider again a comparison between the Mengzi and the Xunzi 荀子 for their notion of human nature. Besides the claim that the notion of human nature is relatable to both, there is also a claim more subtly advanced in the act of setting up the comparison, namely, that the Mengzi and the Xunzi can indeed be placed one next to the other as comparata. There is a whole range of possibilities to support the claim. One could take both simply as being texts, although one would still have to be clear on what one means by that (the editions by D. C. LAU and John Knoblock or some bamboo slips?). Or one could take both as an expression of something: for instance, one could ask whether the Mengzi and the Xunzi are both expressions of one great Chinese philosophical tradition which runs a different course than Western philosophical tradition, expressions of 
Confucianism over against Daoism or rather expressions of two different schools within Confucianism (ren 仁 vs. $l i$ 禮)? Each of these expressions seems very clearly to pose very different claims on a different level of analysis. The point is that by turning on the Mengzi and the Xunzi as two comparata, one has cashed in on one of these or other possible claims. My contention is that what one takes the Mengzi and the Xunzi to be "two of" will influence the range of possible conclusions that might be drawn from comparing them for the notion of human nature. For one thing, it will predetermine whether or not a comparison in respect of the notion of human nature will even be among the considered options.

The problematic of the "pre-comparative" tertium brings up the aspects of distinguishability, determinability, and countability, which cannot be treated here satisfactorily but should nonetheless be noticed. The importance of what one takes the comparata to be "two of" (or three, or four, or five of) suggests that comparability may be related to countability. To place one comparatum next to the other means that one distinguishes between them and that one determines them along some criterion of difference and hence of identity, which then also is the basis for counting and speaking of several comparata. In other words, to claim to have put two or more "things" one next to the other means to claim that one has not only distinguished (which could be purely negatively) but determined them in some respect (e.g., as being "things"), which makes them, it seems, countable and comparable in the first place. ${ }^{22}$ The "criterion of identity" is apparently nothing but another name for the tertium comparationis and the "pre-comparative" tertium. ${ }^{23}$ In most comparisons (say, between two horses, two texts, twenty authors, or three different cultures), it is not at all difficult to establish the "precomparative" tertium. The possibility of the very use of a plural relies on a "criterion of identity," and any plural used to specify the comparata indicates a "pre-comparative" tertium.

\subsection{Against Incomparability}

The "pre-comparative" tertium may be more difficult to establish in cases where no specification of the comparata by means of a common general term is given. Imagine, for instance, a comparison between prime numbers and the Gobi desert. Can they be put one next to the other so that we can speak of them as being two of something? In such a case, it seems either that the "pre-comparative" tertium has to be found by a stroke of ingenium or that it can simply be claimed that the two are incomparable, perhaps even so by definition, which would mean that they can be distinguished but not be compared. Foucault's discussion of Borges's Chinese encyclopedia might come to mind, where "absurdity destroys the and of enumeration by making impossible the in where the things enumerated would be divided up" (Foucault 2002: xvii). One form in which such a challenge frequently comes is in claims of incomparability on the basis of

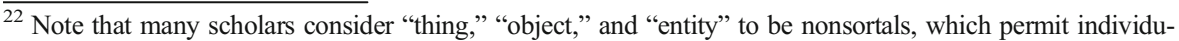
ation but resist countability for the reason that there is no definitive answer to the question of "how many things are there in a given place?" (Wiggins 2001: 75-76). Whether a comparison requires individuation or countability and how my use of "determination" relates to this, is worthy of further exploration. Here, I mention it to illustrate how discussions over sortals may contribute to a philosophy of comparison.

${ }^{23}$ The locus classicus for the "criterion of identity" is in Frege's Grundlagen der Arithmetik, §62 (see Frege 1960: 73).
} 
incommensurability. I think that these claims suffer from an imprecision if they are advanced to suggest overall incomparability.

Such an incomparability is for instance claimed in Chapter 41 of the Mozi 墨子, where it is recorded that "different classes are not comparable" (yi lei bu bi 異類不比), which is so because of the impossibility of "measurement" (liang 量). ${ }^{24}$ The explanation offered in Chapter 43 for this passage is the following:

Difference: Of wood and night, which is the longer? Of knowledge and grain, which is the greater? Of the four things — rank, family, good conduct and price - which is the most valuable? Of the tailed deer and the crane, which is the higher? Of the cicada and the zither, which is the more mournful? (Johnston 2010: 475)

Surely incommensurable classes can be compared at least insofar as they are precisely that, namely classes. I can say that there is wood in the one class but not in the other where there is night, which cannot be measured along any possible measure of length that might be applied to wood. Hence, as regards that measure, they might be incommensurable. However, this does not imply incomparability of the classes (it rather presupposes it), nor incomparability of wood and night. It simply means that wood and night cannot be compared in a specific regard, namely along a common measure of length. The statement of incommensurability between wood and night strikes me as the very outcome of a comparison, as both in some sense seem to be relatable to measures of length (albeit not to one and the same measure). Moreover, if wood and night are both understood in their quality as members of a class, and that class is understood as one out of several classes, then comparability is granted for these reasons alone.

Let me attempt to try out the claim of incomparability further. Umberto Eco offers a statement in which he seeks to push the question to its limits:

... each of us has introjected into him or her an indisputable fact, namely, that from a certain point of view everything bears relationships of analogy, contiguity and similarity to everything else. One may push this to its limits and state that there is a relationship between the adverb "while" and the noun "crocodile" because-at least - they both appeared in the sentence I have just uttered. But the difference between the sane interpretation and the paranoiac interpretation lies in recognizing that this relationship is minimal, and not, on the contrary, deducing from this minimal relationship the maximum possible. (Eco 1992: 48; italics in the original)

\footnotetext{
$\overline{24}$ The book Mozi is named after Mozi 墨子 (Mo Di 墨翟), roughly a contemporary of Kongzi 孔子 (Confucius), about whom very little is known. The quoted passage is from a part of the book often referred to as the "dialectical chapters" of the Mohist Canon (Mo jing 墨經), which it is believed were written by Later Mohists and are famed for posing scores of interpretational and textual problems. The chapters include the Canon (C) and Explanations of the Canon (E). Note that the statement of the Later Mohists is not unlike Aristotle's that there is no comparison possible between things of different genera (Aristotle 1936: 425-428), that is, if the Mohist lei 類 and Aristotle's $\gamma \dot{\text { ć} \eta \eta ~ c a n ~ b e ~ s a i d ~ t o ~ b e ~ a b o u t ~ t h e ~ s a m e ~ t h i n g ~ o r, ~ a t ~ l e a s t, ~ a b o u t ~}$ something sufficiently similar. Interesting in this context is Mozi B64, which reads: "C: When things belong together under one criterion this completes a class - for example, the collecting together of squares. The explanation lies in 'squareness.' E: One: When squares complete a class they all have the criterion although they may be different; if some are wood and some are stone this doesn't harm their being grouped together as squares. They complete a class such as 'squares.' Things are all like this" (Johnston 2010: 549).
} 
This is not yet the limit, I would submit. For a distinction between the adverb "while" and the noun "crocodile" makes for a good comparison in any grammar or etymology (mind that the two also rhyme well, at least in English...). How about the word "while" and a living crocodile? What are they "two of"? I would think that one could find a respect and hence a commonality on which to base a comparison. That the basis may indeed be minimal does not mean that there is no basis. Nor does it mean that overly minimal bases in any way recommend themselves for comparison.

\subsection{External Relations as Basis for Comparison}

If taken strictly it is clear that claims of incomparability do not mean to say that there is no tertium against which that which is claimed to be incomparable could be compared, but rather that the tertium in question is not relatable to one or all comparata, at least not in a suggested specific manner. The idiom of "apples and oranges" otherwise would not have much meaning, given that "apples" and "oranges" of course can be compared in many regards (both are fruits, have a taste, etc.). From a certain point of view, as many authors from Thomas Aquinas (Aquinas 1952, VII.8) to Umberto Eco have stated, everything is similar to everything else. It should be stressed that along a minimal conception of commonality (one that bases its claim on the tertium being equally relatable to both comparata) there are plenty of ways to ensure comparability by means of relying on an external relation. This view has been articulated most clearly by G. E. Moore in his Some Main Problems of Philosophy:

Whatever white patch you take, it is obviously not true, that nothing in the Universe except white patches resemble it at all. On the contrary absolutely everything in the Universe must resemble it in a sense. Absolutely everything in the Universe must resemble it in one respect at least - in respect of the fact that they are both in the Universe. That is to say, there certainly is a sense in which absolutely everything in the Universe resembles everything else: everything does resemble everything else in at least one respect. (Moore 1953: 331)

"Being in the universe" expresses a property possessed by each of two comparata. Whether the property in this case (or in any other) is internal or external and whether it is warranted to frame the issue in terms of internal versus external relations is of no concern to the present argument. Moore himself goes on to distinguish between internal and external resemblance by conceding that he is unable "to define what is meant by internal likeness, as distinct from external likeness," although he is convinced that something important is surely meant. All that is of interest here is the implication of the possibility of taking something like an external relation as basis for a comparison. For Moore, an external resemblance rests on two "things" sharing the "common property" of standing in "a common relation to other things" (Moore 1953: 331). The example that Butchvarov uses for such an external relation are the shades of two colors resembling each other by virtue of "being liked by Mary," what is also called a "Cambridge" property (Butchvarov 1966: 42-43).

The possibility of external relations as basis for comparison implies that any comparata are comparable simply by virtue of possibly standing in a common relation to something to which they are otherwise thought unrelated. The shades of two colors 
could well be thought of completely unrelated to a Mary who likes or dislikes them. But that they can also be thought of as related to a Mary and that anything can be thought of in this manner demonstrates, I think, the soundness of the claim that anything is comparable with anything in some respect. This holds for the word "while" and a living crocodile as much as for prime numbers and the Gobi desert. Putting another spin on it by exchanging "being liked by Mary" to "being of interest to me" or "being of interest to the person doing the comparison," the full significance of external relations as basis for comparison becomes clear. In cases where no specification of the comparata by means of a common general term is given (i.e., unlike in the example of two "shades of colors"), some such external relation might play the role of the "precomparative" tertium.

As a matter of fact, many comparative studies including studies in comparative philosophy may initially be guided precisely by such a resemblance or dissemblance with no basis other than the comparata being of some considerable interest to the person doing the comparison. Whoever sets out to compare, say, classical Confucianism and Cicero might initially be driven by such a consideration, being not yet quite clear on what commonality is supposed to sustain the comparison. Alternatively, some initially asserted commonality may become unwarranted in the process of comparison; whereupon some continued interest steps in as the guiding tertium of the comparison until some new commonality is asserted, and so on. What started out as a comparison of the philosophies of classical Confucianism and Cicero might end up as one of the religious dimensions in each (e.g., if in one or both no "philosophy" whatsoever can any longer be ascertained). That a commonality based on an external relation such as that of "being of interest to me" is indeed possible (and in certain stages of a comparative study perhaps even advantageous) again does not mean that it particularly recommends itself in any way as the guiding tertium of the comparison, at least not if it is to arouse some interest among one's scholarly peers.

\section{What and How Is It That "Comparative Philosophy" Compares?}

"Comparative philosophy," I have somewhat boldly stated, can lay claim to an independent status because it rests on largely unquestioned conventional notions of comparison. What grants this independence is the restricted focus on some specific comparata, which are considered to be expressive of philosophical difference, such as civilizations, nations, traditions, cultures, narratives, and worldviews (not to mention collective minds, souls, or thought). Because of its prominence in contemporary "comparative philosophy," I will focus on the notion of culture, but much of what I have to say may be said of other notions as well. In fact, in much writing, scholars are not very strict when it comes to specifying the "pre-comparative" tertium of their comparata.

This is also the case in essays which theoretically deal with "comparative philosophy." Panikkar, for example, offers us a working definition of "comparative philosophy": "the philosophical study of one or some problems in the light of more than one tradition" (Panikkar 1988: 122). When laying out his notion of "imparative philosophy," which he favors over the one of "comparative philosophy," he uses such telling phrases as "the different philosophical experiences of other people" or "the distance 
between two (or more) cultures, which have independently developed in different spaces (topoi) their own methods of philosophizing and ways of reaching intelligibility along with their proper categories" (Panikkar 1988: 130). In yet another passage, Panikkar claims that his method of diatopical hermeneutics functions between two different topoi, bringing "one culture, language, philosophy into another culture, language, or religion, making it understandable" (Panikkar 1988: 133). How do the notions of traditions, philosophical experiences of people, cultures, spaces, languages, and religions all hang together? I take this vagueness, which is in no way unique to Panikkar, as an indication that in "comparative philosophy" the basis of comparison and the problematic of the tertium are normally not questioned.

Let us assume for a moment that we are dealing with a comparative philosopher strictly referring to cultures as the comparata of his or her choice. The assertion that goes with this choice is the one of cultural difference, often coupled with another assertion, namely that cultural difference entails philosophical difference. ${ }^{25}$ However, any difference presupposes at least a minimal commonality (on the basis of which it can be different in this or that respect). Any double assertion of cultural and philosophical difference hence presupposes a tertium in the sense that both comparata are said to be "cultures with a philosophy of their own" (or to be relatable to such a notion). It remains to be determined in each such comparative study what precisely is understood by the terms "culture" and "philosophy." It is however not my main contention that "comparative philosophy" lacks critical reflection in that regard. Rather, what I am contending is that a few lines into a text marked as a contribution to "comparative philosophy" one encounters talk of "intercultural philosophy," usually without any indication of the mentioned double assertion and without any reasons why this tertium has been chosen over others.

The point is not that "intercultural philosophy" does not make sense. However, simply to assume that cultures are the carriers of relevant philosophical difference (or sameness) is - in the absence of reasoned argument - either naïve or deceptive, and cannot be the standard and measure of comparative philosophy. The burden to show that culture is indeed a useful tertium lies on those pursuing "intercultural philosophy." 26 Nevertheless, prima facie, I do not see any reason why philosophical difference may not also or rather be claimed for differences of gender, age, profession, class, or philosophical position, which all cut across so-called cultures. ${ }^{27}$ What about the distinction

\footnotetext{
$\overline{25}$ There are of course also comparative philosophers who assume or assert cultural difference but precisely are out to deny philosophical difference. The (empirical) claim then is that one and the same philosophical point can be traced within different cultures. Note, however, that "culture" remains a relevant tertium.

${ }^{26}$ I should be clear on my use of the notions of comparative philosophy, "comparative philosophy," and "intercultural philosophy." I take the first to refer to any philosophy that proceeds within a comparative setting (which means that different philosophies of course can but do not have to constitute the comparata; hence, I distinguish between comparative philosophy and the comparison of philosophies). By "comparative philosophy" I mean the mainstream of what goes under that rubric as a philosophical subdiscipline, and which I claim is closely linked to "intercultural philosophy," by which I understand any philosophy that proceeds within a comparative setting by drawing on culture as philosophically relevant tertium. "Intercultural philosophy" thus is understood as a subform of comparative philosophy. It should be noted that in academic discourse "comparative philosophy" and "intercultural philosophy" are often distinguished differently. Some distinguish between "comparative philosophy" as seeking valid judgments on philosophically relevant issues across cultures and "intercultural philosophy" as concerned about the communication processes among philosophical traditions, while others take the one as an interest in the history of philosophy (comparative philosophy) and the other as one in systematic philosophizing (intercultural philosophy).

${ }^{27}$ Holenstein argued strongly for the relevance of intracultural differences (Holenstein 1998: 353-354).
} 
between colonizers and colonized? Is not colonialism part of the experiences of many people? One rather odd consequence of presupposing culture as the philosophically relevant tertium is that comparing Mengzi and Aristotle turns out to be "comparative philosophy," while comparing Plato and Aristotle does not (unless of course one is willing to make the case that Plato and Aristotle are authors within two different cultures rather than one and the same culture; cf. Fleming 2003: 262). What about Derrida and Heidegger or Plato and Heidegger? Are we dealing with one or two cultures? And, if you think that Plato and Heidegger indeed belong to different cultures, does that difference account for their philosophical differences? If it does not account for all but only for some of their philosophical differences, then you seem to acknowledge that there can be philosophical difference without cultural difference. Needless to say, many have treated their subject-matter precisely in this manner, readily asserting philosophical differences between, say, the Socratic Plato and the Plato of the Nomoi or the Marburg and the Baden school of Neo-Kantianism without any recourse to culture as explanans for the differences. The common regards in which such differences are assertible are likely to recommend themselves for comparative philosophy, at least in the absence of further supportive argument as likely as any difference in culture recommends itself.

\section{Conclusion}

There are three points that I would like to mention in concluding my discussion of comparison and the problematic of the tertium. First, the voiced skepticism against claims of incomparability and against a reductionist view of comparative philosophy as intercultural philosophy is in no way meant to entail the view that we are without criteria to distinguish meaningful from meaningless comparisons. That anything can be compared with anything does not mean that anything can be compared valuably with anything and should be compared with anything. To the contrary, focus on the tertium comparationis and the "pre-comparative" tertium precisely offers a means to evaluate comparisons. What are the chosen comparata? What are the ontological commitments that go with these comparata? Are there arguments presented for the choice and if so do we find them persuasive? A question that might be worthy of further exploration in this context is whether and under what circumstances it is advisable to opt for a tertium that poses minimal claims as to its being relatable to both comparata, hence easily finds common assent, but risks the charge of being merely "formal" or for a tertium that poses maximal claims, is suggestively controversial but risks being vague to the point of obscurantism. Together with Garrett Barden, I have tried out the first option in a comparison of two texts, Leviticus and the Analects, on the minimal basis that in both texts there are recorded rhetorical situations such as someone speaking to somebody else, someone issuing a command, someone asking a question and another answering, and so on (cf. Weber and Barden 2010). Following the second option (surely dominant in much comparative work), for example, leads to comparisons that take the two texts as emblematic expressions of respectively the Abrahamic and the Confucian tradition or Western and Chinese culture.

Secondly, it strikes me that the problematic of the tertium leads one to the role of the person who makes the comparison. What is compared with what, and in what respect this is done, depends largely on the aims and interests of that person and on much more. Nelson Goodman offers an intuitive example: 
Consider baggage at an airport check-in station. The spectator may notice shape, size, color, material, and even make of luggage; the pilot is more concerned with weight, and the passenger with destination and ownership. Which pieces of luggage are more alike than others depends not only upon the properties they share, but upon who makes the comparison, and when. (Goodman 1972: 445)

I would claim that what is here exemplified on the basis of an airport check-in situation similarly holds for comparisons between Chinese and Japanese culture or Greek and Chinese antiquity. Melissa Lane has rightly remarked that "the phenomena available to comparative philosophy are always already interpreted phenomena" (Lane 2009: 591; italics in original). ${ }^{28}$ I have above mentioned the importance of ontological commitments for a comparison. These ontological commitments are likely to be at least to some degree consistent with the ontological views of the person doing the comparison, and might be contested. Moreover, besides the interpretational and ontological dependence there are also purposes that go into comparisons, and focussing on the problematic of the tertium might be helpful to make clear just what purpose is at play. Why does one wish to compare Greek and Chinese antiquity? Obviously, one might do so to satisfy many interests, personal, historical, philosophical, scientific, heuristic, but also political. Which of these purposes is central might in a given case be hard to disentangle, both for the analyser of the comparison as much as for the person who makes the comparison. Yet to the extent that the purpose might indeed be a political one, it should be made transparent. The concern is that those who insist on philosophical difference because of an asserted cultural difference might be pursuing an undeclared political agenda, say, of cultural conservatism or cultural progressivism, both of which might easily be turned into an instrument of those in power.

Thirdly and finally, I should be clear on the point that my raising the problematic of the tertium in the rationalistic way pursued in this essay is not to demonstrate once and for all that no other way of comparison is conceivable. If it can be shown that there is a way of comparing which does not upon reflection rely on a tertium but proceeds by some other way (e.g., bare similarity), then that should be a most welcome finding. But it surely seems necessary that it should be possible to describe that way in a nonthetic manner based on a reasoning that is open to criticism. Butterflies and Chinese will not do, at least not if that way of comparison without a tertium is to be useful for the practice and research of philosophy.

Acknowledgments This paper has profited from the critical comments and suggestions offered by many friends and colleagues, particularly Garrett Barden, Martin Beckstein, Arindam Chakrabarti, Hans-Johann Glock, Roland Kley, and Timothy Murphy, as well as from points raised in discussion after public presentation at the National University of Singapore, especially by LoY Hui-chieh, Lisa Raphals, Neiladri Sinhababu, and Sor-hoon TAN, and at conferences in Glasgow and Kandersteg. I am also indebted to my colleagues at the URPP Asia and Europe of the University of Zurich and there particularly to the participants of several doctoral seminars on the topic of comparison. I should like to express also my gratitude to the two anonymous referees for their helpful remarks.

\footnotetext{
${ }^{28}$ Lane is replying to an Aristotelian proposal by Nicholas Bunnin and YU Jiyuan (Bunnin and Yu 2001) to save the phenomena in the study of comparative philosophy, which is itself an interesting contribution to the problem discussed in this article.
} 


\section{References}

Agamben, Giorgio. 2009. Signatura rerum: Zur Methode. Frankfurt a.M.: Suhrkamp.

Albrecht, Michael. 1985. "Einleitung." In Christian Wolff, Rede über die praktische Philosophie der Chinesen, Latin and German edition, edited by Michael Albrecht. Hamburg: Meiner.

Albus, Vanessa. 2001. Weltbild und Metapher: Untersuchungen zur Philosophie im 18. Jahrhundert. Würzburg: Königshausen \& Neumann.

Aquinas, Thomas. 1952. Quaestiones disputatae de potentia Dei / On the Power of God. Westminster: The Newman Press. <http://dhspriory.org/thomas/QDdePotentia7.htm\#7:8> (last viewed 21 January 2014)

Aristotle. 1936. Physics. Edited and trans. by David Ross. Oxford: Oxford University Press. 1963. Categories and De Interpretatione. Trans. by J. L. Ackrill. Oxford: Oxford University Press. 2000. Nicomachean Ethics. Trans. and edited by Roger Crisp. Cambridge: Cambridge University Press.

Bouveresse, Jacques. 1999. Prodiges et vertiges de l'analogie. Paris: Éditions Raisons d'Agir.

Brunswig, Alfred. 1910. Das Vergleichen und die Relationserkenntnis. Leipzig und Berlin: Teubner.

Bunnin, Nicholas, and YU Jiyuan. 2001. "Saving the Phenomena: An Aristotelian Method in Comparative Philosophy." In Two Roads to Wisdom? Chinese and Analytical Philosophical Traditions, edited by Bo Mou. Chicago: Open Court.

Butchvarov, Panayot. 1966. Resemblance and Identity: An Examination of the Problem of Universals. Bloomington and London: Indiana University Press.

Eco, Umberto. 1992. "Overinterpreting texts." In Interpretation and Overinterpretation, edited by Stefan Collini. Cambridge: Cambridge University Press.

Elberfeld, Rolf. 1999. "Überlegungen zur Grundlegung 'komparativer Philosophie'.” Allgemeine Zeitschrift für Philosophie 24.2: 125-154.

Engels, Friedrich. 1968. “[Konspekt über] 'Das Kapital’ von Karl Marx. Erster Band.” In Karl Marx/Friedrich Engels: Werke, vol. 16. Berlin: Dietz Verlag.

Fleming, Jesse. 2003. “Comparative Philosophy: Its Aims and Methods.” Journal of Chinese Philosophy 30.2: 259-270.

Foucault, Michel. 1983. This Is not a Pipe. Trans. by James Harkness. Berkeley: University of California Press.

2002. The Order of Things: An Archaeology of the Human Sciences. London: Routledge.

Frege, Gottlob. 1960. The Foundations of Arithmetic. 2nd rev. ed. Trans. by J. L. Austin. New York: Harper Torchbooks.

Glock, Hans-Johann. 1996. A Wittgenstein Dictionary. Malden: Blackwell Publishing.

Goodman, Nelson. 1972. "Seven Strictures on Similarity." In Problems and Projects. Indianapolis: Hackett Publishing Company.

Halbfass, Wilhelm. 1985. "India and the Comparative Method." Philosophy East and West 35.1: 3-15.

Heil, John. 2003. From an Ontological Point of View. Oxford: Clarendon Press.

Holenstein, Elmar. 1998. Kulturphilosophische Perspektiven. Frankfurt am Main: Suhrkamp.

Husserl, Edmund. 1901. Logische Untersuchungen-Zweiter Theil: Untersuchungen zur Phänomenologie und Theorie der Erkenntnis. Halle: Max Niemeyer.

Johnston, Ian. 2010. The Mozi: A Complete Translation. New York: Columbia University Press.

Kant, Immanuel. 1800. Logik: ein Handbuch zu Vorlesungen. Edited by Gottlobb Benjamin Jäsche. Königsberg: bey Friedrich Nicolovius.

1992. Lectures on Logic. Trans. and edited by J. Michael Young. Cambridge: Cambridge University Press.

Lane, Melissa. 2009. "Comparing Greek and Chinese Political Thought: The Case of Plato's Republic." Journal of Chinese Philosophy 36.4: 585-601.

Lloyd, Geoffrey (G.E.R.). 2004. Ancient Worlds, Modern Reflections: Philosophical Perspectives on Greek and Chinese Science and Culture. Oxford: Oxford University Press.

Locke, John. 1997. An Essay Concerning Human Understanding. Edited by Roger Woolhouse. London: Penguin Books.

Markosian, Ned. 1998. "Simples.” Australasian Journal of Philosophy 76.2: 213-228.

Marx, Karl. 1962. Das Kapital. Band 1. In Karl Marx/Friedrich Engels: Werke, vol. 23. Berlin: Dietz Verlag.

Moore, George Edward. 1953. Some Main Problems of Philosophy. London: Allen and Unwin.

Moore, Samuel, and Edward Aveling, trans. n.d. "Synopsis of Capital." < http://www.marxists.org/archive/ marx/works/1867-c1/1868-syn/ch01.htm> (last viewed 19 January 2014).

Mou, Bo. 2010. “On Constructive-Engagement Strategy of Comparative Philosophy: A Journal Theme Introduction." Comparative Philosophy 1.1: 1-32. 
Murphy, Timothy, and Ralph Weber. 2010. "Confucianizing Socrates and Socratizing Confucius: On Comparing Analects 13:18 and the Euthyphro." Philosophy East and West 60.2: 187-206.

Musil, Robert. 1990. "Mind and Experience: Notes for Readers Who Have Eluded the Decline of the West (1921)." In Precision and Soul: Essays and Addresses, edited by Burton Pike and David S. Luft. Chicago: The University of Chicago Press.

Panikkar, Raimundo. 1988. "What is Comparative Philosophy Comparing?" In Interpreting Across Boundaries: New Essays in Comparative Philosophy, edited by Gerald James Larson and Eliot Deutsch. Princeton: Princeton University Press.

Petrus Hispanus. 1972. Tractatus called afterwards Summulae logicales. Edited by Lambertus Marie de Rijk. Assen: Van Gorcum.

Reding, Jean-Paul. 2004. Comparative Essays in Early Greek and Chinese Rational Thinking. Aldershot: Ashgate.

Rodriguez-Pereyra, Gonzalo. 2002. Resemblance Nominalism: A Solution to the Problem of Universals. Oxford: Clarendon Press.

Russell, Bertrand. 1912. The Problems of Philosophy. London: Oxford University Press.

Schenk, Günter, and Andrej Krause. 2001. "Vergleich.” In Historisches Wörterbuch der Philosophie, edited by Joachim Ritter, Karlfried Gründer, and Gottfried Gabriel, vol. 11. Basel: Schwabe Verlag.

Smid, Robert W. 2009. Methodologies of Comparative Philosophy: The Pragmatist and Process Traditions. Albany: State University of New York Press.

Thiel, Christian. 2004. "tertium comparationis." In Enzyklopädie Philosophie und Wissenschaftstheorie, vol. 4, edited by Jürgen Mittelstraß. Stuttgart: Metzler.

Weber, Ralph. 2013. “'How to Compare?'-On the Methodological State of Comparative Philosophy." Philosophy Compass 8.7: 593-603.

, and Garrett Barden. 2010. "Rhetorics of Authority: Leviticus and the Analects Compared." Asiatische Studien/Études Asiatiques 64.1: 173-240.

Wiggins, David. 2001. Sameness and Substance Renewed. Cambridge: Cambridge University Press.

Wittgenstein, Ludwig. 1958. Philosophische Untersuchungen/Philosophical Investigations. 2nd ed. Trans. by G. E. M. Anscombe. Oxford: Blackwell.

1965. The Blue and Brown Books. New York: Harper Torchbooks.

Wolff, Christian. 1981. "Von den fruchtbaren Begriffen." In Gesammelte Werke, 1. Abt. Deutsche Schriften, vol. 21.2. Hildesheim and New York: Georg Olms.

1985. Rede über die praktische Philosophie der Chinesen, Latin and German ed. Edited by Michael Albrecht. Hamburg: Meiner.

Wong, David B. 2002. "Reasons and Analogical Reasoning in Mengzi." In Essays on the Moral Philosophy of Mengzi, edited by LIU Xiaogan and Philip J. Ivanhoe. Indianapolis: Hackett Publishing Company.

Zhang, Xianglong. 2010. "Comparison Paradox, Comparative Situation and Interparadigmaticy: A Methodological Reflection on Cross-Cultural Philosophical Comparison." Comparative Philosophy 1.1: 90-105. 